\title{
Relação família-paciente no transtorno obsessivo-compulsivo
}

\section{M aria Luisa Guedes}

Departamento de Psiquiatria da Universidade Federal de São Paulo (Unifesp/EPM) e Pontifícia Universidade Católica de São Paulo. São Paulo, SP,

\begin{abstract}
This article is based on the notion that obsessive-compulsive behaviors are perpetuated by negative reinforcement. The assessment of such contingencies inevitably leads to the examination of family's interactions, crucial for establishing the severity and prognosis of the disorder. The notion of family accommodation is analyzed as reinforcement contingencies that act upon family members and patients. Family members, often desperate and unaware of behavior practices provide inconsistent and intermittent consequences for the patient's behaviors. As a result, abnormal behaviors worsen, get chronic, and there's a general deterioration of the quality of life. It is suggested that, as a part of the routine, the clinician should evaluate systematically and carefully the family's interactions in order to plan and assess effectively his/her therapeutic interventions.
\end{abstract}

Keywords Obsessive-compulsive disorder. Family.

\section{Introdução}

Embora muitos estudos têm avaliado e proposto a inclusão de familiares no tratamento de pessoas com comportamentos obsessivo-compulsivos, ${ }^{1-5}$ poucos analisam os processos de interação familiar como responsáveis pelo desenvolvimento e pela gravidade de tais comportamentos.

O objetivo deste artigo é analisar relações familiares como mantenedoras e produtoras do transtorno obsessivocompulsivo (TOC).

A análise apresentada baseia-se no estudo de Calvocoressi et al, ${ }^{6}$ que, partindo da suposição de que a investigação sobre as interações entre família e paciente é fundamental em função das conseqüências para os paciente e a família, desenvolveram uma Escala de Acomodação Familiar. Os autores definiram "acomodação" como a participação da família nos comportamentos associados aos rituais do paciente e às modificações na rotina diária familiar.

Se o TOC for considerado como repertórios mantidos por reforço negativo - fuga e esquiva,$-{ }^{7,8}$ ao lado de compreender sua origem, é importante compreender as variáveis que os mantêm. Na base dessas variáveis, estão as interações sociais (especialmente as familiares) mantidas pelo indivíduo.

Análise das relações familiares revela que a acomodação familiar é uma característica das famílias de pacientes com TOC. ${ }^{69}$ Ou seja, os familiares têm participação direta nos rituais e muitas vezes transformam o cotidiano da família baseados nos comportamentos compulsivos.

Para compreender esses resultados, é só atentar para o fato de que a presença de uma pessoa com comportamentos obsessivo-compulsivos inevitavelmente produz mudanças na vida daqueles que com ela convivem. Como afirmam LivingstonVan Noppen et al," "talvez em nenhum outro transtorno psiquiátrico seja a família tão inexoravelmente envolvida na doença como no TOC".

Esse envolvimento pode variar desde ajudar em tarefas simples, falar infinitas vezes sobre o mesmo assunto, submeterse a rituais de descontaminação ou organização ou mesmo conformar-se com a impossibilidade de utilizar cômodos da própria casa.

Como afirmam Koran et al, ${ }^{10}$ pacientes com TOC relataram deterioração nas situações de trabalho, escola e família, tanto nas relações sociais quanto no desempenho de tarefas relacionadas a essas três instâncias. Isto significa, muito freqüentemente, a perda do emprego, o abandono da escola, o rompimento de laços de amizade e a ausência de atividades de lazer. Geralmente a família enfrenta essas conseqüências sem qualquer suporte econômico, emocional e mesmo sem qualquer orientação específica profissional de como lidar com o paciente.

Parece razoável supor esse contexto em que se insere a família - de um lado premida pela ausência de recursos, e de outro, pelas necessidades do paciente - como o fator responsável pela generalidade da acomodação familiar.

A ausência de suporte profissional específico para a família conduz à suposição de que ela age de maneira que não é planejada, sistemática e avaliada. Ao contrário, a ação da família é natural, intuitiva, inconsciente, emocional. Essa oposição de estilos de atuação reflete, como sugere Skinner, ${ }^{11}$ a oposição entre duas formas de controle: o comportamento governado por regras e o comportamento sob controle das contin- 
gências.* São interações controladas por suas conseqüências que descrevem a família analisada no presente trabalho: ela age sob controle das conseqüências imediatas, pelas consequiências imediatas daquela determinada atuação, e a relevância das conseqüências depende das circunstâncias específicas em que cada interação se dá. Diante, por exemplo, da mesma demanda para participar de um mesmo ritual do paciente, em alguns momentos a família poderá atender essa solicitação, em outros poderá até se antecipar e fazer coisas pelo paciente, em outros poderá ignorar suas solicitações e, também, poderá punir essa demanda em outras ocasiões. $\mathrm{Na}$ interação com o paciente, a família age sob controle de um conjunto de fatores: desde a presença e a ação específica do paciente, até as próprias condições emocionais do familiar, todos são fatores condicionantes daquele momento em que ocorre uma determinada interação. Em síntese, a interação da família com o paciente - nesse caso, a acomodação familiar é marcada por um padrão que pode ser chamado de inconsistente.**

A inconsistência como marca das interações entre a família e o paciente de TOC implica uma outra característica importante para a compreensão dos processos comportamentais: a intermitência do reforço.*** Ao agir inconsistentemente, a família acaba reforçando determinadas ações algumas vezes e outras, não (por exemplo, diante de perguntas repetidas, a família ora responde, ora deixa de responder por algum tempo, para depois voltar a responder). Também como produto da inconsistência, o padrão de reação da família se encaixaria em um estado de reforço intermitente variável: varia a quantidade de tempo que a família 'agüenta' não reagir ao paciente e/ou varia o número de solicitações que são necessárias por parte do paciente antes que a família finalmente responda. A intermitência, especialmente quando acrescida de esquemas variáveis, é responsável pela manutenção e pelo fortalecimento dos comportamentos assim conseqüenciados. Ou seja, ao reagir dessa forma, a família acaba produzindo padrões de comportamento extremamente resistentes à extinção. ${ }^{12}$

A inconsistência da família, em suas interações com o paciente, está, assim, na base da deterioração do repertório do paciente e da alta resistência à extinção desses repertórios. As conseqüências conflitantes que seguem as ações do paciente acabam por desorientá-lo e por torná-lo cada vez mais incapacitado e mais dependente da família. Além disso, a intermitência do reforço acaba por torná-lo cada vez mais persistente e aparentemente mais imune a tentativas de diminuir seus comportamentos compulsivos. Contrariamente às expectativas da família, apesar de todo seu desgaste, esforço e envolvimento, suas ações acabam, dessa forma, por agravar a situação do paciente.

Além de se marcarem pela inconsistência e intermitência, as ações da família em relação ao paciente são basicamente respostas de fuga/esquiva; respostas que têm a função de adiar/ eliminar/diminuir a intensidade da estimulação aversiva representada pelos comportamentos e pelas demandas do paciente.

Nesse contexto, maior gravidade parece ser sinônimo de maior aversividade para a família e, portanto, maior acomodação, mais respostas de fuga/esquiva. A intensidade do estímulo aversivo, entretanto, não é o único fator controlador de respostas de fuga/esquiva. Sabe-se também que se a intensidade da estimulação aversiva for gradualmente aumentada, é como se essa intensidade fosse relativizada. ${ }^{13}$ Se for considerado que o padrão comportamental dos pacientes muda gradativamente, modelado inclusive por suas interações com a família, tem-se uma situação em que a família vai sendo gradualmente exposta à estimulação aversiva cada vez mais intensa. Assim, comportamentos aparentemente de pouca gravidade podem evocar respostas de fuga/esquiva dos familiares; enquanto outros de maior gravidade podem não evocar prontamente respostas de fuga/esquiva da família.

A longa exposição da família aos comportamentos obsessivocompulsivos ameniza o impacto destes sobre ela e pode, inclusive, ir gradualmente preparando-a para um agravamento dos mesmos. Além disso, a longa exposição a essa situação pode fazer com que a família não mais reconheça como alterações na sua vida aquilo que faz em função do paciente.

Mesmo assim, a família reage diferencialmente a alguns padrões comportamentais do paciente. Aparentemente, alguns tipos de rituais, mais do que outros, produzem acomodação familiar. Rituais de limpeza interferem mais no cotidiano da família e da casa, impedindo a realização de atividades importantes para a família. Do mesmo modo, a lentidão do paciente deve consistente e sistematicamente interferir na vida familiar. Possivelmente, portanto, é o quão intrusivos se tornam esses rituais e essas conseqüências que determinam o grau de acomodação familiar.

Compreendendo o fenômeno da acomodação familiar, pode-se entender o grau de desgaste e estresse presentes na família. Além do desgaste costumeiramente chamado de físico, possivelmente envolvido em qualquer situação aversiva, contingências de fuga/ esquiva geram, como um de seus subprodutos, sentimentos e sensações que são aversivos e desgastantes para os participantes

\footnotetext{
*Skinner, em 1969, distingue comportamento modelado por contingências - ações cujas probabilidades futuras são alteradas pelas conseqüências imediatas que produzem, pelas mudanças ambientais que provocam - e comportamento governado por regras - ações que, embora tenham suas probabilidades alteradas pelas mudanças ambientais que produzem, são evocadas por estímulos antecedentes verbais, por descrições da ação e de suas conseqüências.

**Livingston-Van Noppen et al² destacam como tendo um padrão de ação inconsistente um tipo de família, que chama de uma "família dividida". Diferentemente, o que se afirma neste estudo é que a inconsistência é uma marca presente nas relações família-paciente, independentemente de outras características que possam ser utilizadas para categorizar tipos de famílias.

***Entende-se por reforço qualquer evento que segue a emissão de uma ação e altera a probabilidade de ocorrência de ações semelhantes no futuro. Respostas podem ser reforçadas a cada ocorrência e, nesse caso, diz-se que o esquema de reforço que mantém tais respostas é contínuo; ou respostas podem ser mantidas por reforços que não são consequiência de todas as ocorrências e, nesse caso, o esquema de reforço é chamado de intermitente.
} 
dessas interações. Como Sidman ${ }^{8}$ aponta, reforço negativo ou contingências de fuga/esquiva submetem as pessoas a um estresse contínuo, a ficar temerosas diante de qualquer mudança ou novidade, a viver "uma vida de quieto desespero".* A presença de controle aversivo marcando o cotidiano, ainda que se mantenha uma aparência de "naturalidade e normalidade", tem um importante impacto sobre as pessoas. Mesmo a recusa em participar ou se envolver nos comportamentos obsessivos e compulsivos acarreta estresse. As negativas de participação e as providências tomadas na direção de se opor aos comportamentos obsessivo-compulsivos do paciente geram conflitos e tensão. Na verdade, só poder-se-ia esperar ausência de desgaste se fosse possível supor uma família que conseguisse ignorar, não reagir ao paciente, o que, na imensa maioria das vezes, é impossível.

As considerações propostas neste estudo enfatizam a necessidade de considerar, de maneira exaustiva, as relações entre a família e o paciente para que se possa planejar e executar intervenções com alguma chance de sucesso. Um passo nessa direção pode ser tornar rotina do profissional especializado no tratamento desses pacientes a investigação sistemática da família e de suas relações com o paciente.

\section{Referências}

1. Lenane M. Families in obsessive-compulsive disorder. In: Rapoport J, editor. Obsessive-compulsive disorder in children and adolescents. Washington (DC): American Psychiatric Press; 1989.

2. Livingston-Van Noppen B, Rasmussen S, Eisen J, McCartney L. Family function and treatment in obsessive-compulsive disorder. In: Jenike MA, Baer L, Minichiello WE, editores. Obsessivecompulsive disorders: theory and management. Chicago: Year Book Medical Publishers; 1990.

3. Knox L, Albano A, Barlow D. Parental involvement in the treatment of childhood obsessive-compulsive disorder: a multiplebaseline examination involving parents. Behav Ther 1996;27:93.

4. Pollock R, Carter A. The familial and developmental context of obsessive-compulsive disorder. Child Adolesc Psych Clin North Am 1999;8:461-79.

5. Piacentini J. Cognitive behavioral therapy of childhood obsessivecompulsive disorder. Child Adolesc Psych Clin North Am 1999;8:599-616.
6. Calvocoressi L, Lewis B, Harris M, Trufan S, Goodman W, McDougle C, et al. Family accommodation in obsessivecompulsive disorder. Am J Psychiatry 1995;152:441-3.

7. Foa E, Tillmanns A. The treatment of obsessive-compulsive neurosis. In: Goldstein A, Foa E, editores. Handbook of behavioral interventions: a clinical guide. New York: John Wiley \& Sons; 1980.

8. Sidman M. Coerção e suas implicações. São Paulo: Editorial Psy; 1995.

9. Guedes ML. Transtorno obsessivo-compulsivo: um estudo do processo de acomodação familiar [dissertação]. São Paulo: Escola Paulista de Medicina da Universidade Federal de São Paulo; 1997.

10. Koran L, Thienemann ML, Davenport R. Quality of life for pacients with obsessive-compulsive disorder. Am J Psychiatry 1996;153:783-8.

11. Skinner BF. Contingencies of reinforcement. New York: Appleton-Century-Crofts; 1969.

12. Skinner BF. Science and Human Behavior. New York: MacMillan Company; 1953.

13. Catania C. Learning. New Jersey: Prentice Hall; 1992.

Correspondência: Maria Luiza Guedes

Laboratório de Psicologia Experimental - PUC/SP

Rua João Ramalho, 301, Perdizes - 05008-001 São Paulo, SP

E-mail: ancpto@exatas.pucsp.br

\footnotetext{
*Deve-se enfatizar que esses mesmos efeitos colaterais afetam também o paciente. Aliás, Sidman ${ }^{8}$ aponta como um dos subprodutos do reforço negativo o fato de que pessoas submetidas a esse tipo de contingência só podem dar conta de "rotinas preestabelecidas, de uma maneira estereotipada, mecânica, ou compulsiva." (grifo dos autores) (p.109)
} 